\title{
A comprehensive methodology based on NTME/GC-MS data and chemometric tools for lemons discrimination according to geographical origin
}

\author{
José A. Figueira $^{\mathrm{a}}$, Priscilla Porto-Figueira ${ }^{\mathrm{a}}$, Jorge A.M. Pereira ${ }^{\mathrm{a}}$, José S. Câmara ${ }^{\mathrm{a}, \mathrm{b}, *}$ \\ ${ }^{\text {a }}$ CQM - Centro de Química da Madeira, Universidade da Madeira, Campus da Penteada, 9000-039 Funchal, Portugal \\ ${ }^{\mathrm{b}}$ Faculdade das Ciências Exactas e Engenharia, Universidade da Madeira, Campus Universitário da Penteada, 9020-105 Funchal, Portugal
}

\section{A R T I C L E I N F O}

\section{Keywords:}

Lemon

Eureka variety

Peel

NTME-GC-MS

VOCs

Geographical origin

Multivariate statistical analysis

\begin{abstract}
A B S T R A C T
In this work we report an innovative and high throughput methodology involving Needle Trap Microextraction (NTME) combined with GC-MS analyis and chemometric processing, to obtain comprehensive volatile fingerprints for authenticity purposes. This approach ewill allow to characterize the volatile composition of lemon peels (exocarp) (Eureka variety) from different geographical regions of Portugal (mainland and Madeira Island), Argentine and South Africa as useful tool to identify geographic molecular markers with potential for discrimination according to their geographical origin. The most important parameters affecting NTME, namely extraction and headspace volumes, sample temperature and equilibration time, were optimized using an experimental design (DoE). Overall, 75 volatile organic compounds (VOCs), belonging to different chemical groups, namely monoterpenes, sesquiterpenes, alcohols and carbonyl compounds, were identified. D-limonene, $\alpha$-pinene, $\beta$-pinene, sabinene, $\beta$-myrcene and $\gamma$-terpinene were the dominant volatiles identified, accounting for more than $50 \%$ of the volatile composition of selected lemons varieties. The VOCs data matrix obtained was submitted to both supervised (Orthogonal Projections to Latent Structures Discriminant Analysis, OPLS-DA) and unsupervised (Hierarchical Clustering Analysis, HCA) statistics, allowing to discriminate lemons based on the volatomic fingerprint of its peel. The VOCs with the larger contribution to the geographical origin classification included butanal, $\alpha$-pinene, $\alpha$-thujene, 1-butanol, 2-heptanone, D-limonene, 2-methyl-2-heptenal, nonanal, decanal, 1-octanol, limonene oxide, $\beta$-caryophyllene and 2,6-dimethyl-2,6-octadiene, suggesting their potential as geographical markers. This study shows the potential of NTMS/GC-MS combined with multivariate statistical analysis as a powerful and rapid strategy to obtain volatile fingerprints of different food matrices and support the certification of their origin and authenticity.
\end{abstract}

\section{Introduction}

Agro-food products, including citrus fruits, contain in their composition distinctive geographic characteristics arising from the terroir and edafo-climatic conditions. These factors influence metabolomic signatures and consequently the quality and value of the product [1,2]. In turn, this will determine the acceptance by consumers. In this way, the use of geographical indication for a given product allows producers to obtain premium prices and market recognition.

Lemon (Citrus limon) is one of the most popular citrus fruit, after orange and mandarin, with a world production ranging 4.2 million tons, mainly concentrated in USA, Argentina, Spain, Italy and Mexico (FAO, 2014) [1,2]. Lemon is rich in a myriad of secondary metabolites widely used in pharmaceutical, nutraceutical, food and cosmetic industries. In addition to vitamin C, lemon contains phytochemicals, including polyphenols (flavonoids and non-flavonoids), limonoids and terpenoids, which play a key role as nutraceuticals [3,4]. Some of these metabolites have been shown to possess anticancer, antimicrobial, antioxidant and antidiabetic properties [3-6]. Furthermore, essential oils from lemon and other citrus fruits are considered excellent alternatives

\footnotetext{
Abbreviations: CNTs, carbon nanotubes; DoE, experimental design; DVB, divinylbenzene; EI, electron-impact mode; GC-MS, gas chromatography-mass spectro-

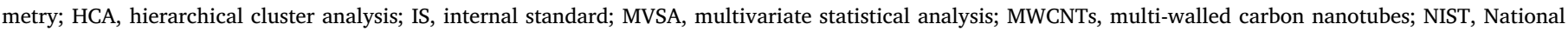

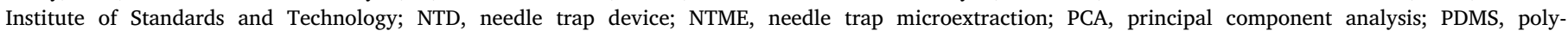
dimethylsiloxane; PTFE, polytetrafluoroethylene; RT, retention time; SPME, solid phase microextraction; VOCs, volatile organic compounds

* Corresponding author.

E-mail address: jsc@uma.pt (J.S. Câmara).
} 
to the chemical additives in the food industry $[1,5,6]$, encompassing both the need for safety and the consumers demand for natural food components.

The volatile composition of food matrices is one of the most important factors influencing flavour and consequently consumer's acceptance [4]. In lemon, it has been widely reported that the metabolomic pathways and corresponding volatile composition are influenced by several factors related with the genotype (existence of numerous hybrid cultivars), maturation and geography [1,4]. Currently, different methods are used to establish the volatile composition of food matrices and food-related samples. Gas chromatography-mass spectrometry (GC-MS) constitutes golden standard instrumental technique for VOCs analysis in in a wide range of differentiated samples [7-9]. However, the previous sample preparation, often disregarded, is crucial to concentrate VOCs and remove interferences, particularly from complicated matrices $[9,10]$. Classical extraction techniques, including solvent extraction, distillation and headspace techniques, are mainly based on the solubility or volatility of the VOCs. Such approaches allow the definition of fingerprints of the volatile composition and a comprehensive information on the flavour/aroma of the target sample. Currently, solid phase microextraction (SPME) is a well-established technique in the field of VOCs analysis [11-13], but its extraction capacity is hindered by the small amount of sorbent normally used $(60-100 \mu \mathrm{m})$. As a nonexhaustive technique, SPME efficiency depends of the mass transfer between a small portion of analytes toward the extracting media, and large amounts of analytes remain in the sample solution/matrix $[11,14,15]$. Such drawback is more critical for low abundant VOCs, whose identification is often not possible. In recent years needle trap microextraction (NTME) has been introduced as a simple and fast isolation/extraction technique for VOCs in different matrices [16-19]. NTME is mechanically more robust than SPME, since the sorbent particles are protected inside of the needle trap device (NTD) (Fig. 1) $[18,19]$. Moreover, it is an exhaustive extraction technique, meaning that the sample VOCs can be completely extracted, at least tills the breakthrough (sorbent bed saturation) occurs. In addition, the NTME sensitivity can be improved by increasing the sample volume and its capacity can be expanded by increasing the volume of the packed sorbent in the NTD [11,18-20]. Since NTME requires small sample volumes to extract large amount of analytes, normally a sampling volume smaller than the breakthrough volume is used [11,16-19,21]. The analyte concentration $\left(\mathrm{C}_{0}\right)$ can be calculated using the following equation: $\mathrm{n}=\mathrm{C}_{0} \mathrm{~V}$, where $n$ is the extracted mass by the NTD, $C_{o}$ is the concentration of analyte, and $V$ is the sample volume [21, 22].

In NTME, VOCs are forced to cross over the sorbent packed inside the needle, being the analytes trapped into sorbent [15-19,23,24]. Thus, the choice of an appropriate sorbent material is one of the critical factors to obtain a good recovery and high enrichment factors [11,16-19]. There are several sorbents commercially available, such as divinylbenzene (DVB), polydimethylsiloxane (PDMS), DVB and Carboxen particles Carbopack X, Tenax TA, Porapak Q, as well different sorbents combinations [9,10,15-19,23]. Nevertheless, to further improve selectivity and specificity towards target compounds, new sorbent materials, including synthetic polymers and nanostructured based materials, are being developed. This includes SiO2@cis-9-octadecenoic acid, molecularly imprinted sol-gel xerogel [9] carbon nanotubes (CNTs), CNT/silica composite, multi-walled carbon nanotubes/silica composite (MWCNTs/Si), graphene $(\mathrm{G})$, graphene nano-platelets silica

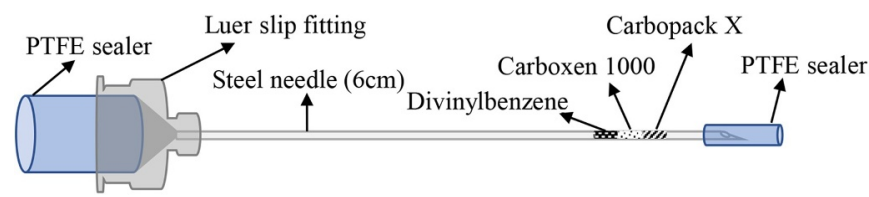

Fig. 1. Design of the NTD used in this study (NeedleEx): sharp end with triplebed sorbent (DVB/Car1000/CarX) configuration. composite (G/Si), polythiophene-silver nanocomposite (PT-Ag), graphene oxide (GO) and nanoporous silica aerogel (NPSA) [9,15,24,25]. Other experimental factors such as extraction time, sample amount and headspace volume, are key parameters on the NTME efficiency.

Desorption of the analytes require quick (few seconds) single-stage thermal desorption, being the analytes efficiently transferred to the GCMS system with minimum or none carryover [15,23,24,26]. Under the same GC injection conditions, the thermal desorption is faster in NTME than in SPME, overcorrecting the downside of the SPME technique with a highest sensitivity and speed [7,24]. As summarized by Barkhordari et al., NTME has been used mainly for isolation of VOCs from air, water and exhaled breath samples [24].

The main purpose of this work was to explore the potential of the integrated analytical approach using NTME/GC-MS combined with chemometric tools, for the identification of geographical markers of lemons from the same cultivar (Eureka) cultivated in different countries - Portugal (mainland and Madeira Island), Argentina and South Africa. Key NTME experimental parameters that can influence the extraction efficiency, namely extraction temperature, equilibration time, headspace volume and sample amount, were optimized. The acquired data set of non-targeted fingerprints was then processed using multi-dimensional chemometric strategies to identify volatile markers able to discriminate lemons (Eureka variety) according to their geographical origin. As far we are aware, this is the first work reporting the high potential of NTME as an extraction approach for food research.

\section{Materials and methods}

\subsection{Chemicals and Materials}

All standards used for VOCs confirmation (purity higher than 98.5\%) and the $n$-alkanes mixture containing $C_{8}-C_{20}$ straight-chain alkanes in hexane, were obtained from Sigma-Aldrich (St. Louis, MO, USA). Helium, ultra-pure grade (Air Liquide, Portugal) was used as carrier gas in the GC system. Clear glass screw cap vials for extraction with PTFE/silica septa were purchased from Supelco (Bellefonte, PA, USA). The NTDs used in this work, "NeedleEx", were custom manufactured by Shinwa Ltd., Japan $(60 \mathrm{~mm} \times 0: 41 \mathrm{~mm}$ id, $0.72 \mathrm{~mm}$ od, triple bed configuration Divinylbenzene/Carboxen 1000/Carbopack X DVB/Car1000/CarX) and purchased to PAS Technology (Magdala, Germany). Prior to their use, NTDs were conditioned in a special custom-made heating device (PAS Technology, Magdala, Germany) at $250{ }^{\circ} \mathrm{C}$, under permanent helium flow for at least $20 \mathrm{~h}$ to eliminate any contaminations from the manufacturing process or shipping. Afterwards, both ends of the needles were sealed with Teflon caps and stored. Before being used, the NTDs were conditioned again for $30 \mathrm{~min}$ in the heating device.

\subsection{Lemon samples}

Lemon samples from the same variety (Eureka), but cultivated in different regions (Portugal - mainland and Madeira island, Argentina and South Africa) were selected randomly from a local market. After selection, the peel (exocarp) of each lemon was individually collected, and immediately stored under nitrogen at $-80^{\circ} \mathrm{C}$, in $250 \mathrm{mg}$ aliquots until analysis.

\subsection{Optimization of needle trap microextraction (NTME)}

To increase the NTME efficiency, key experimental parameters were optimized [19,27], including (i) the extraction temperature $\left(30{ }^{\circ} \mathrm{C}\right.$, $40{ }^{\circ} \mathrm{C}$ to $50{ }^{\circ} \mathrm{C}$ ), (ii) the equilibration time $(10,30,50 \mathrm{~min}$ ), and (iii) the headspace volume (20, 30 and $40 \mathrm{ml}$ ), using a 'Design of Experiments' (DoE) optimisation approach. All extractions were performed in triplicate. The DoE is relatively straightforward and can greatly facilitate the optimisation assays, generating a model with 16 combinations. The 
resulting data matrix was submitted to statistical treatment.

\subsubsection{NTME procedure}

Following the optimization step, $250 \mathrm{mg}$ of sample was placed into $20 \mathrm{ml}$ of extraction tubes and added $100 \mu \mathrm{L}$ of 2-heptanol (30 ppm) as internal standard. The extraction tubes were sealed, and the system equilibrated for $10 \mathrm{~min}$ at $50 \pm 1{ }^{\circ} \mathrm{C}$. Then, the NTDs pre-attached to a disposable $1 \mathrm{~mL}$ syringe were inserted into the headspace of the extraction tube, and $30 \mathrm{~mL}$ of the gas phase were manually loaded through the sorbent (30 withdraw-loading cycles, average speed $10 \pm 2 \mathrm{~mL} \mathrm{~min}^{-1}$ ). After the extraction, the syringe was discarded and the NTD was sealed in both ends with PTFE caps. Finally, the NTD was injected into GC-MS system at $250{ }^{\circ} \mathrm{C}$ for 60 seconds to attain the thermal desorption of the extracted VOCs. Before the next extraction, the sorbent was reactivated by placing the NTDs in a conditioner at $250{ }^{\circ} \mathrm{C}$ under constant flow of helium (purity 5.0, Air Liquid, Portugal) at a constant pressure of 1 bar for $30 \mathrm{~min}$. Unless indicated, all procedures were repeated with at least three different samples $(N=3)$ and analysed in triplicate $(n=3)$.

\subsection{Gas chromatography-quadrupole mass spectrometry analysis (GC-qMS)}

The analysis was carried out on an Agilent $6890 \mathrm{~N}$ gas chromatograph system (Agilent Technologies, Palo Alto, CA, USA) coupled with an Agilent 5975 quadrupole inert mass selective detector. The separation of the extracted compounds was performed on a BP-20 fused silica capillary column $(60 \mathrm{~m} \times 0.25 \mathrm{~mm}$ I.D. $\times 0.25 \mu \mathrm{m}$ film thickness $)$. Splitless injection was employed using helium as carrier gas at a constant flow rate of $1.0 \mathrm{~mL} \mathrm{~min}{ }^{-1}$. Oven temperature conditions were: $45{ }^{\circ} \mathrm{C}$ (held for $2 \mathrm{~min}$ ), followed by a gradient temperature ramp from $45{ }^{\circ} \mathrm{C}$ held for $1 \mathrm{~min}$, then up to $90{ }^{\circ} \mathrm{C}$, held for $3 \mathrm{~min}$ at a rate of $2{ }^{\circ} \mathrm{C} \mathrm{min}^{-1}$, followed by a flow rate of $3^{\circ} \mathrm{C} \mathrm{min}^{-1}$ until $160^{\circ} \mathrm{C}$ (held for $6 \mathrm{~min}$ ), and finally from $160^{\circ} \mathrm{C}$ to $220^{\circ} \mathrm{C}$ held for $15 \mathrm{~min}$ at a rate of $6{ }^{\circ} \mathrm{C} \mathrm{min}^{-1}$. The injection and ion source temperatures were $250{ }^{\circ} \mathrm{C}$ and $230{ }^{\circ} \mathrm{C}$, respectively. The mass spectra of the compounds were acquired in electron-impact (EI) mode at $70 \mathrm{eV}$. The electron multiplier was set to the auto tune procedure. Data acquisition was performed in scanning mode (mass range $m / z=35-300 \mathrm{amu}$; six scans per second). Chromatograms and spectra were recorded and processed using the Enhanced ChemStation software for GC-MS (Agilent Technologies, Palo Alto, CA, USA). VOCs identification was based on: (i) comparison between the GC retention times (RT) of the chromatographic peaks with those, when available, of authentic standards run under the same conditions; (ii) mass spectra were also compared with the data system library (NIST, 2005 software, Mass Spectral Search Program v.2.0d; Nist 2005, Washington, DC). Single VOM peak was considered as identified compound when its experimental spectrum corresponded with a score of over $80 \%$ that present in the library; (iii) determination of Kovat's retention index (KI) values using a $\mathrm{C}_{8}-\mathrm{C}_{20} n$-alkanes series and the values were compared, when available, with values reported in the scientific literature for similar columns. Once again, the values were compared, when available, with values reported in the literature for similar chromatographic columns.

Chromatographic peak areas, expressed in arbitrary units (a.u.) of area, were determined using the Full Scan chromatogram, and were used as an approach to estimate the relative content of each volatile metabolite. For semi-quantification purposes, each sample was injected in triplicate, and the chromatographic peak areas (as kcounts amounts) were determined by a reconstructed full-scan chromatogram using for each compound some specific quantification ions: these corresponded to base ion (m/z $100 \%$ intensity), molecular ion $\left(\mathrm{M}^{+}\right)$, and another characteristic ion for each molecule.

\subsection{Multivariate statistical analysis}

The multivariate data analysis (MVDA) was performed using the MetaboAnalyst 4.0 web-based tool [28]. The raw GC-qMS data was firstly pre-processed by normalization (to sample median, data transformation by cubic root and data scaling by autoscaling). The analysis of variance (ANOVA, $\mathrm{p}<0.05$ ), including PCA, was used for variable reductions and to convert a set of highly correlated variables to a set of independent variables by using linear transformations. Hierarchical cluster analysis (HCA) was carried out using the 40 most significant VOCs identified in lemon samples obtained by ANOVA (generated using Ward algorithm and Pearson distance analysis). The ratio of VOCs was first calculated by average algorithm and Pearson distance analysis, and then the metabolic alterations were demonstrated as $\log 10$ (ratio) depicting distinct clustering patterns among the studied groups. Principal component analysis (PCA) was used as an unsupervised pattern for statistical procedure that converts a set of observations of possible correlated variables into a set of values of linearly uncorrelated variables (principal components) using orthogonal transformation. This proof of concept work clearly shows the potential of NTME coupled to GC-MS in the definition of geographical markers for lemon varieties. Future works involving a higher number of samples will certainly facilitate data analysis and improve the robustness of the statistical models and obtained results.

\section{Results and discussion}

\subsection{Optimization of NTME Procedure}

A properly optimized method ensures good accuracy, precision and sensitivity. Accordingly, the most relevant parameters affecting NTME sample amount, extraction temperature, equilibration time and headspace volume, were optimized using a DoE optimization approach (Table 1.SM, Supplementary Material). Upon the different experiments performed (Fig. 2), DoE predicts the influence of the parameters considered and the outcome of different combinations along the maximum and minimum values obtained for each parameter.

\subsubsection{Sample amount}

The sample amount should be selected based on the established distribution constant $\left(\mathrm{K}_{\mathrm{D}}\right)$ of the volatile composition. Depending on the sorbent and nature of the volatiles, the $\mathrm{K}_{\mathrm{D}}$ may vary substantially, leading to different extraction yields. The dependence of the extraction efficiency on the sample amount gives useful information on NTME method development. Our initial assay reveal that $1 \mathrm{~g}$ of lemon peel was excessive, contributing to a poor chromatographic resolution (data not shown). The sample amount was then adjusted to $250 \mathrm{mg}$ of lemon peel, with the respective chromatograms showing a good peak resolution and sensitivity. In addition, the effect of the particle size of the lemon peel amount was also evaluated by comparing 1 single piece of $250 \mathrm{mg}$ vs $250 \mathrm{mg}$ of smaller slices of $\pm 1 \mathrm{~mm}^{2}$ (obtained using the ULTRA-TURRAX T25 disperser). Not surprisingly, the smaller slices provide a higher surface area, allowing more efficient extractions and so this condition was used in all further assays.

\subsubsection{Extraction temperature}

The temperature employed during extraction is one of the most important parameters affecting the efficiency of NTME. This is mainly because high extraction temperatures improve the kinetic of mass transfer from the bulk sample to the headspace, favouring the efficiency of the extraction procedure $[10,23,25]$. However, too high temperatures may cause the thermal degradation of the most labile VOCs and decrease the trapping capability of the sorbent, due to the exothermic effect of the sorption process $[25,29]$. In this work, the best results were obtained using $50{ }^{\circ} \mathrm{C}$ as extraction temperature (Fig. 2). It was observed a direct correlation between the extraction temperature and the total 
Table 1

Volatile organic compounds (VOCs) identified in lemon peel from Eureka variety, from different geographic origins.

VOCs (organized by chemical family) $\quad \mathrm{RT}^{\mathrm{a}}(\mathrm{min}) \quad \mathrm{RI}^{\mathrm{b}}$ calc $\quad \mathrm{RI}^{\mathrm{c}}{ }_{\text {lit }} \quad$ Relative Peak Area $\left(\times 10^{-2}\right)^{\mathrm{d}}(\mathrm{RSD}<10 \%)$

Portugal (mainland) Portugal (Madeira Island) Argentine South Africa

\begin{tabular}{|c|c|c|c|c|c|c|c|c|}
\hline \multicolumn{9}{|c|}{ Aldehydes } \\
\hline $1^{\mathrm{e}}$ & Acetaldehyde & 5.0 & 725 & 723 & 0.64 & 0.58 & 0.26 & 1.35 \\
\hline 4 & Butanal & 6.7 & 843 & 860 & 0.12 & 0.12 & 0.02 & 0.07 \\
\hline 8 & Pentanal & 9.0 & 946 & 968 & 0.77 & 0.89 & 0.14 & 0.36 \\
\hline 16 & Hexanal & 12.7 & 1045 & 1083 & 140.34 & 139.49 & 20.07 & 30.71 \\
\hline 37 & 2-Methyl-2-heptenal & 28.4 & 1298 & 1342 & $\mathrm{nd}^{\mathrm{f}}$ & nd & nd & 0.41 \\
\hline 39 & Nonanal & 31.2 & 1343 & 1390 & 3.51 & 12.39 & 8.31 & 11.06 \\
\hline \multirow{2}{*}{49} & Decanal & 37.4 & 1446 & 1481 & 1.15 & 1.83 & 1.84 & 1.48 \\
\hline & & & & Total & 146.53 & 155.26 & 30.65 & 45.44 \\
\hline \multicolumn{9}{|c|}{ Esters } \\
\hline 3 & Methyl acetate & 6.0 & 798 & 813 & 0.23 & 0.13 & 0.05 & 0.11 \\
\hline 26 & Ethyl hexanoate & 21.0 & 1190 & 1213 & 0.82 & nd & nd & nd \\
\hline \multirow[t]{2}{*}{44} & Ethyl octanoate & 34.0 & 1385 & 1428 & 0.18 & 0.07 & nd & nd \\
\hline & & & & Total & 1.24 & 0.20 & 0.05 & 0.11 \\
\hline \multicolumn{9}{|c|}{ Higher Alcohols } \\
\hline 5 & Methanol & 7.0 & 860 & 866 & 12.04 & 20.08 & 5.12 & 21.08 \\
\hline 6 & Ethanol & 7.7 & 899 & 917 & 44.36 & 6.97 & 0.89 & 2.24 \\
\hline 19 & 1-Butanol & 15.5 & 1099 & 1148 & 0.30 & 0.38 & 0.09 & nd \\
\hline 20 & 1-Penten-3-ol & 16.4 & 1116 & 1161 & 1.45 & 1.76 & 0.58 & 1.11 \\
\hline 32 & (Z)-2-Penten-1-ol & 25.8 & 1263 & 1304 & 0.85 & 1.15 & nd & 0.42 \\
\hline 33 & 2-Heptanol (IS) ${ }^{g}$ & 25.9 & 1265 & 1319 & 1.00 & 1.00 & 1.00 & 1.00 \\
\hline 36 & 1-Hexanol & 28.1 & 1294 & 1339 & 0.63 & 1.07 & 0.30 & 0.63 \\
\hline 38 & 3-Hexen-1-ol & 30.2 & 1327 & 1384 & 1.18 & 1.71 & 1.08 & 2.80 \\
\hline 40 & 3-tert-Butylphenol & 31.8 & 1352 & - & 0.37 & 0.49 & 0.13 & 0.56 \\
\hline 53 & 1-Octanol & 40.1 & 1494 & 1530 & 0.30 & 0.62 & 1.72 & 0.69 \\
\hline \multirow[t]{2}{*}{58} & 1-Nonanol & 44.9 & 1597 & 1661 & nd & nd & 0.53 & 1.07 \\
\hline & & & & Total & 62.48 & 35.23 & 11.45 & 31.60 \\
\hline \multicolumn{9}{|c|}{ Ketones } \\
\hline 2 & Acetone & 5.8 & 785 & 775 & 0.44 & 0.79 & 0.18 & 0.76 \\
\hline 22 & 2-Heptanone & 17.8 & 1140 & 1180 & 4.07 & 3.46 & 1.00 & nd \\
\hline \multirow[t]{2}{*}{35} & 6-Methyl-5-hepten-2-one & 27.2 & 1282 & 1322 & 0.16 & 0.42 & 0.12 & 0.54 \\
\hline & & & & Total & 4.67 & 4.67 & 1.30 & 1.29 \\
\hline Mo & & & & & & & & \\
\hline 9 & Fenchene & 9.4 & 957 & - & 2.21 & 2.41 & 0.74 & 6.93 \\
\hline 10 & Tricyclene & 10.2 & 985 & 1003 & 6.29 & 8.34 & 3.18 & 15.19 \\
\hline 11 & $\alpha$-Pinene & 10.8 & 1001 & 1007 & 351.84 & 608.49 & 236.22 & 1315.55 \\
\hline 12 & $\alpha$-Thujene & 10.9 & 1003 & 1017 & 95.58 & 150.98 & 59.17 & nd \\
\hline 14 & $\alpha$-Fenchene & 11.9 & 1027 & 1052 & 6.51 & 8.43 & 2.98 & 16.52 \\
\hline 15 & Camphene & 12.2 & 1034 & 1063 & 33.44 & 56.10 & 22.61 & 120.12 \\
\hline 17 & $\beta$-Pinene & 14.3 & 1078 & 1094 & 1533.12 & 2408.58 & 1010.20 & 3005.88 \\
\hline 18 & Sabinene & 14.8 & 1086 & 1109 & 405.39 & 589.44 & 285.60 & 635.61 \\
\hline 21 & $\beta$-Myrcene & 17.0 & 1127 & 1169 & 308.92 & 507.92 & 207.17 & 740.51 \\
\hline 23 & $\alpha$-Terpinene & 17.8 & 1141 & 1181 & 8.67 & 2.61 & 1.16 & 4.11 \\
\hline 24 & D-Limonene & 20.0 & 1176 & 1188 & 6179.13 & 8098.05 & 3138.40 & 12291.42 \\
\hline 25 & $\beta$-Phellandrene & 20.1 & 1177 & 1197 & 70.31 & 105.95 & 43.58 & 136.96 \\
\hline 27 & (E)-Ocimene & 21.3 & 1196 & 1240 & 6.64 & 15.45 & 7.58 & 18.56 \\
\hline 28 & $\gamma$-Terpinene & 22.2 & 1210 & 1243 & 1277.39 & 1742.15 & 753.91 & 2247.46 \\
\hline 29 & Z-Ocimene & 22.3 & 1210 & 1245 & 13.18 & 26.60 & 9.04 & 27.72 \\
\hline 30 & o-Cymene & 23.2 & 1225 & 1260 & 103.82 & 88.27 & 24.78 & 61.49 \\
\hline 31 & Terpinolene & 24.1 & 1239 & 1274 & 85.05 & 122.41 & 55.45 & 161.47 \\
\hline 43 & p-Cymenene & 33.8 & 1383 & 1421 & 0.55 & 0.53 & 0.31 & 1.03 \\
\hline & & & & Total & 10488.03 & 14542.70 & 5862.07 & 20806.52 \\
\hline Ses & & & & & & & & \\
\hline 54 & $\alpha$-Santalene & 41.6 & 1526 & 1555 & 0.58 & 1.25 & 0.39 & 0.25 \\
\hline 55 & $\alpha$-Bergamotene & 42.3 & 1542 & 1584 & 31.29 & 34.09 & 8.79 & 25.20 \\
\hline 56 & $\beta$-Caryophyllene & 42.6 & 1548 & 1615 & 18.58 & 18.49 & 4.84 & 14.82 \\
\hline 57 & $\alpha$-Himachalene & 43.4 & 1566 & 1649 & 1.05 & 1.08 & 0.66 & 0.72 \\
\hline 59 & $\beta$-Santalene & 45.0 & 1599 & 1649 & 0.78 & 0.84 & 0.21 & 0.56 \\
\hline 60 & 2,6-Dimethyl-2,6-octadiene & 45.2 & 1604 & - & 4.89 & 2.82 & 0.61 & 2.69 \\
\hline 63 & (Z)- $\beta$-Farnesene & 46.5 & 1636 & 1670 & 1.32 & 1.88 & 0.31 & 0.72 \\
\hline 67 & Valencene & 47.9 & 1669 & 1718 & 15.32 & 52.22 & 21.05 & 49.75 \\
\hline 68 & $\beta$-Bisabolene & 48.3 & 1678 & 1723 & 24.15 & 27.76 & 6.80 & 20.06 \\
\hline 69 & Bicyclogermacrene & 48.5 & 1683 & 1735 & 4.66 & 4.93 & 1.37 & 7.04 \\
\hline 72 & $\alpha$-Panansinene & 49.6 & 1709 & - & 0.80 & 0.54 & 0.09 & 0.17 \\
\hline & & & & Total & 103.42 & 145.91 & 45.12 & 121.97 \\
\hline Oxy & & & & & & & & \\
\hline 41 & Perillene & 32.9 & 1369 & 1415 & 0.23 & 0.31 & 0.09 & 0.35 \\
\hline 45 & Limonene oxide & 34.2 & 1388 & 1442 & 1.07 & 1.12 & 0.29 & 0.99 \\
\hline 46 & trans-Limonene oxide & 34.9 & 1398 & 1472 & 1.64 & 2.10 & 0.33 & 1.49 \\
\hline 47 & trans- $\boldsymbol{\beta}$-Terpineol & 35.2 & 1404 & 1563 & 6.25 & 17.98 & 8.73 & 25.04 \\
\hline 48 & (3R)-(+)-Citronellal & 36.2 & 1423 & 1493 & 6.87 & 14.44 & 4.81 & 12.23 \\
\hline 50 & Camphor & 37.9 & 1455 & 1512 & 0.65 & 2.17 & 0.98 & 2.67 \\
\hline 51 & cis- $\beta$-Terpineol & 39.5 & 1484 & 1616 & 0.84 & 6.19 & 3.55 & 7.88 \\
\hline
\end{tabular}

(continued on next page) 
Table 1 (continued)

\begin{tabular}{|c|c|c|c|c|c|c|c|c|}
\hline \multirow{2}{*}{\multicolumn{2}{|c|}{ VOCs (organized by chemical family) }} & \multirow{3}{*}{$\begin{array}{l}\mathrm{RT}^{\mathrm{a}}(\min ) \\
39.6\end{array}$} & \multirow{3}{*}{$\begin{array}{l}\mathrm{RI}_{\text {calc }}^{\mathrm{b}} \\
1486\end{array}$} & \multirow{3}{*}{$\begin{array}{l}\mathrm{RI}^{\mathrm{c}}{ }_{\text {lit }} \\
1522\end{array}$} & \multicolumn{4}{|c|}{ Relative Peak Area $\left(\times 10^{-2}\right)^{\mathrm{d}}(\mathrm{RSD}<10 \%)$} \\
\hline & & & & & \multirow{2}{*}{$\begin{array}{l}\text { Portugal (mainland) } \\
15.42\end{array}$} & \multirow{2}{*}{$\begin{array}{l}\text { Portugal (Madeira Island) } \\
29.85\end{array}$} & \multirow{2}{*}{$\begin{array}{l}\text { Argentine } \\
11.22\end{array}$} & \multirow{2}{*}{$\begin{array}{l}\text { South Africa } \\
43.73\end{array}$} \\
\hline 52 & Linalool & & & & & & & \\
\hline 61 & Neral & 45.8 & 1619 & 1689 & 9.44 & 41.12 & 15.22 & 45.36 \\
\hline 62 & $\alpha$-Terpineol & 46.4 & 1633 & 1692 & 7.57 & 25.15 & 10.44 & 30.26 \\
\hline 64 & Borneol & 46.6 & 1638 & 1698 & nd & nd & 0.50 & 1.14 \\
\hline 65 & Piperitone & 47.6 & 1662 & 1705 & 0.24 & 0.42 & 0.17 & 0.45 \\
\hline 66 & Neryl acetate & 47.8 & 1666 & 1708 & 46.53 & 44.28 & 11.82 & 64.61 \\
\hline 70 & Geranyl acetate & 49.0 & 1694 & 1752 & 27.21 & 23.90 & 6.72 & 31.47 \\
\hline 71 & (R)-Citronellol & 49.2 & 1699 & - & 2.31 & 2.73 & 1.00 & 2.45 \\
\hline 73 & Perilla aldehyde & 49.9 & 1716 & 1776 & 0.57 & 1.12 & 0.51 & 1.52 \\
\hline 74 & Nerol & 50.5 & 1731 & 1794 & 4.39 & 11.36 & 8.25 & 18.95 \\
\hline \multirow[t]{2}{*}{75} & Geraniol & 52.5 & 1778 & 1840 & 3.75 & 10.40 & 8.24 & 16.41 \\
\hline & & & & Total & 134.99 & 234.63 & 92.89 & 307.02 \\
\hline \multicolumn{9}{|c|}{ Others } \\
\hline 7 & 2-Ethyl-Furan & 8.3 & 922 & 945 & 1.71 & 1.49 & 0.45 & 3.16 \\
\hline 13 & Toluene & 11.1 & 1008 & 1019 & 0.25 & 0.21 & 0.10 & nd \\
\hline 34 & Tridecane & 26.5 & 1273 & 1300 & 0.22 & 0.18 & 0.08 & 0.15 \\
\hline \multirow[t]{4}{*}{42} & Tetradecane & 33.3 & 1375 & 1400 & 0.58 & 0.52 & 0.22 & 0.78 \\
\hline & & & & Total & 2.77 & 2.40 & 0.85 & 4.09 \\
\hline & \multirow{2}{*}{\multicolumn{3}{|c|}{ Total relative peak area (vs Internal standard) }} & & 10944.13 & 15121.04 & 6044.38 & 21318.06 \\
\hline & & & & TOTAL VOCs & 72 & 71 & 71 & 69 \\
\hline
\end{tabular}

VOCs indicated in bold were confirmed against commercial standards.

${ }^{\text {a }} \mathrm{RT}$ : retention time expressed in min.

b $\mathrm{RI}_{\text {calc }}$ : experimental Kovat's index.

c $\mathrm{RI}_{\text {lit }}$ : Kovat's index reported in the literature.

d Relative Peak Area $\left(\times 10^{-2}\right.$ ): (VOC peak area/Internal Standard peak area).

e Peak number ordered by VOC retention time.

f nd: not detected.

$\mathrm{g}$ IS: Internal Standard (2-heptanol).

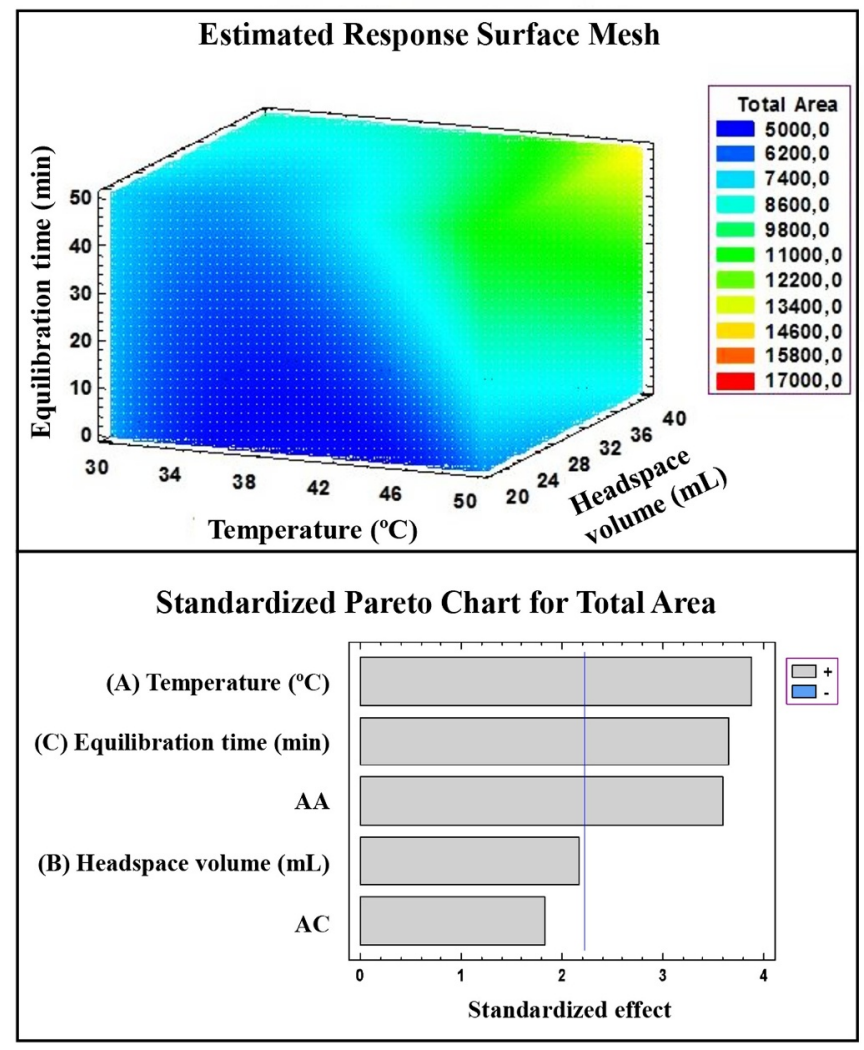

Fig. 2. DoE results as Estimated Response Surface Mesh and Standardized Pareto Chart for Total Area, from different key parameters that influence NTME: Temperature ( $\left(\frac{\mathrm{C}}{\mathrm{C}}\right.$, Equilibration time (min) and Headspace volume $(\mathrm{mL})$. instrument signal. Furthermore, the results listed in Fig. 2 also show that the extraction temperature is the main factor in the extraction process.

\subsubsection{Equilibration time}

NTME, in contrast with SPME, has an exhaustive character and its extraction ability can be extended till the sorbent saturation (breakthrough point) [16-19]. Nevertheless, the selection of a proper equilibration time has direct influence on the amount of the target analytes that will be available to extract and consequently in the sensitivity and precision of the NTME method [16-19]. The results (Fig. 2) shows that the equilibration time was the second most important parameter in the optimization model. A linear correlation among equilibration time and instrument signal was obtained meaning that higher the extraction time, higher the instrument signal (within the time range studied).

\subsubsection{Headspace volume}

Since NTD is an exhaustive technique, the response will be proportional to the sample headspace volume that is loaded through the sorbent $\left(\mathrm{n}=\mathrm{C}_{0} \mathrm{~V}\right)[21,22]$. This agrees with the results obtained in DoE (Fig. 2). According to Trefz et al. [27], the extractive capacity of the sorbent is greater when larger sample headspace volumes are used, at least for a set of model metabolites like isoprene, pentane, toluene and pentanal [18]. In conventional NTDs the breakthrough is about $0.5 \mathrm{mg}$ for a packing length of $1 \mathrm{~cm}$ [30], while for the DVB/CAR/CAR fibre, the breakthrough volume was not reached up to $60 \mathrm{~mL}$ [18] of headspace volume. Based on the results obtained, and to minimize the extraction time, avoid signal saturation on the GC-MS and increase the reusability of the sorbents, $30 \mathrm{~mL}$ was selected as the appropriate headspace sample volume. This selection agrees with the results obtained in DoE (Fig. 2).

\subsection{VOCs profile of lemon peels from different geographical regions}

As can be seen in Fig. 3, the volatile profiles from the peels of the Eureka lemon samples from different geographical regions are quite 


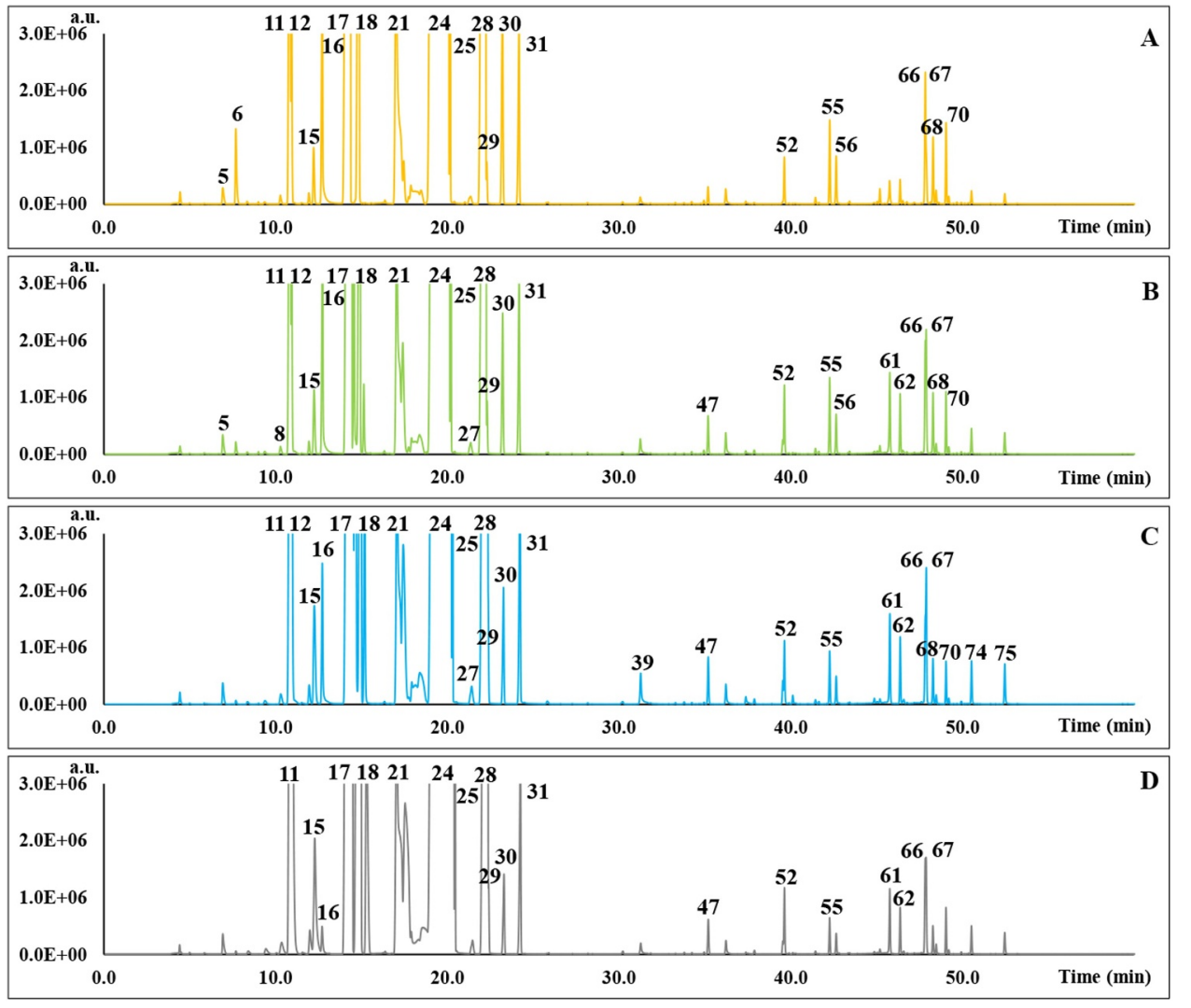

Fig. 3. NTME/GC-MS typical profile of the peel from lemons (Eureka variety) from the regions investigated in the study: Portugal (mainland and Madeira Island), Argentine and South Africa. Legend of the VOCs that contributed with more than $0.05 \%$ to the total peak area: 5- methanol, 6- ethanol, 11- $\alpha$ pinene, 12- $\alpha$-thujene, 15- camphene, 16hexanal, 17- $\beta$-pinene, 18- sabinene, 21- $\beta$ myrcene, 24- d-limonene, 25- $\beta$-phellandrene, 27- (E)-ocimene, 28- $\gamma$-terpinene, 29-(Z)-ocimene, 30- o-cimene, 31- terpinolene, 39- nonanal, 47- trans- $\beta$-terpineol, 52- linalool, 55- $\alpha$ bergamotene, 56- $\beta$-caryophyllene, 61- neral, 62- $\alpha$-terpineol, 66- neryl acetate, 67- valencene, 68- $\beta$-bisabolene, 70- geranyl acetate, 74- nerol, 75- geraniol. similar. The total VOCs identified in each group range from 69 (South Africa) to 72 (Portugal). Overall, 75 different VOCs were identified in all samples based on comparison of mass spectra with the reference database (MS) and calculated retention indices $\left(\mathrm{RI}_{\text {calc }}\right)$ with values reported in the literature $\left(\mathrm{RI}_{\text {lit }}\right)$ for BP-20 fused silica (or equivalent) capillary column (Table 1). The retention indices of the experimental data obtained were in good agreement with those reported on the literature and with the correspondent linear retention, having an $r^{2}=0.995$ (Supplementary Fig. 1). The contribution of each VOC for the total volatile fraction expressed as relative peak area were calculated as follow:

Peak area of analyte/Peak area of internal standard

Despite the apparent similarity in the VOCs profiles obtained for the four lemon samples analysed, there are some distinctive features related with the relative abundance of each VOC and functional groups. As shown in Table 1, the lemons from South Africa seems to be more aromatic than the other groups as the sum of the relative peaks areas is significantly higher (1.5, 2 and 3 times higher than lemons from Madeira, Portugal mainland and Argentine, respectively). Monoterpenes are by far the functional class more abundant in all samples analysed, representing over $95 \%$ of the volatile fractions. This representation is mainly due to D-limonene, followed by $\alpha$-and $\beta$-pinene, $\beta$-myrcene and $\gamma$-terpinene, which are the most abundant VOCs identified in all lemon samples. In contrast, higher alcohols are much more abundant in the Portuguese lemons from mainland when compared with the other groups analysed. A similar trend was observed for aldehydes that are more abundant in the lemons cultivated in Portugal (mainland and Madeira) than the samples from Argentine and South Africa. To obtain a closer snapshot of the importance of each functional class in each type of lemon analysed, the VOCs relative areas were normalized and compared. As can be clearly observed in Fig. 4, although monoterpenes represent almost all lemon VOC composition (ranging from 95 to almost $98 \%$ of the volatile composition), there are significant variations in the abundance of minor classes, particularly aldehydes, higher alcohols, ketones and sesquiterpene hydrocarbons. These features are obviously also evident at the individual VOCs level. Hexanal and ethanol, for instance, are far more abundant in the lemons from Portugal (mainland and Madeira) when compared with Argentine and South Africa lemons. Overall, esters and ketones are among the less abundant classes of VOCs (Fig. 4), but very interesting differences were also observed among the four lemon cultivars analysed. The 2-heptanone, for instance, is four times more abundant in the lemon samples from Portugal (mainland and Madeira) than the lemons form Argentine and it was not detected in the lemons form South Africa. Similarly, esters are very poorly represented in the lemon samples analysed, with only three of such compounds identified, being the most abundant, ethyl hexanoate, only detected in the lemons cultivated in Portugal mainland. Also 2-methyl-2-heptenal was only identified in lemon peels from South Africa, while 1-butanol, 2-heptanone, $\alpha$-thujene and toluene, were not identified in these samples. Overall, these compounds can be considered potential geographic markers and this possibility was assessed using advanced statistical analysis discussed in the next section.

The volatile composition of lemons from Eureka variety has been reported in the literature employing a range of analytical techniques. Lota et al. [31], for instance, identified 22 VOCs, while Zhong et al. [32] identified 34 VOCs and Zhang et al. [33] identified 54 VOCs in Eureka and 67 VOCs in Limonia lemons. By comparison, the 75 VOCs reported in this work is indicative of the higher throughput that NTME allows. In agreement with our results, these reports indicate a richmonoterpene volatile fingerprint for lemons and a similar volatile composition in what concerns to the major VOCs, namely D-limonene, $\beta$-pinene, $\gamma$-terpinene, $\beta$-myrcene and $\alpha$-pinene.

\subsection{Multivariate analysis - Geographic discrimination}

To evaluate the potential of the volatile fingerprints obtained in this 


\section{Representativity of the major VOC classes identified in the different lemons}

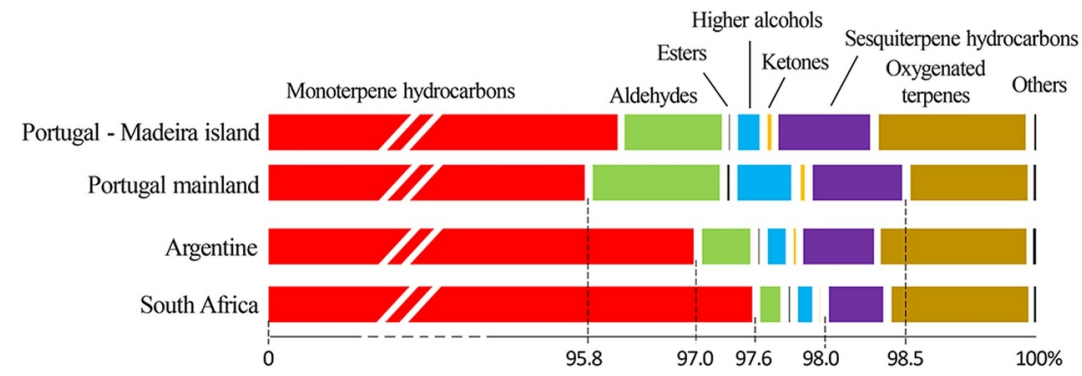

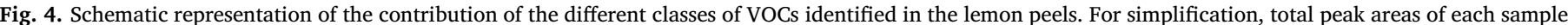
type were normalized and represented as percentage (\%).

Table 2

VOCs responsible for the discrimination of Eureka lemons according to the geographic region of production.

\begin{tabular}{|c|c|c|c|}
\hline Portugal (mainland) & Portugal (Madeira Island) & Argentina & South Africa \\
\hline Butanal & $\alpha$-Thujene & Nonanal & Fenchene \\
\hline Limonene oxide & Toluene & Decanal & Tricyclene \\
\hline (Z)-2-Penten-1-ol & 1-Butanol & Cis- $\beta$-Terpineol & $\alpha$-Pinene \\
\hline$\beta$-Caryophyllene & 2-Heptanone & 1-Octanol & Camphene \\
\hline 2,6-Dimethyl-2,6-octadiene & $\alpha$-Santalene & Nerol & D-Limonene \\
\hline Ethyl hexanoate $^{\mathrm{a}}$ & $\alpha$-Himachalene & Geraniol & 2-Methyl-2-heptenal ${ }^{\mathrm{a}}$ \\
\hline
\end{tabular}

${ }^{a}$ VOC identified only in this geographical region.
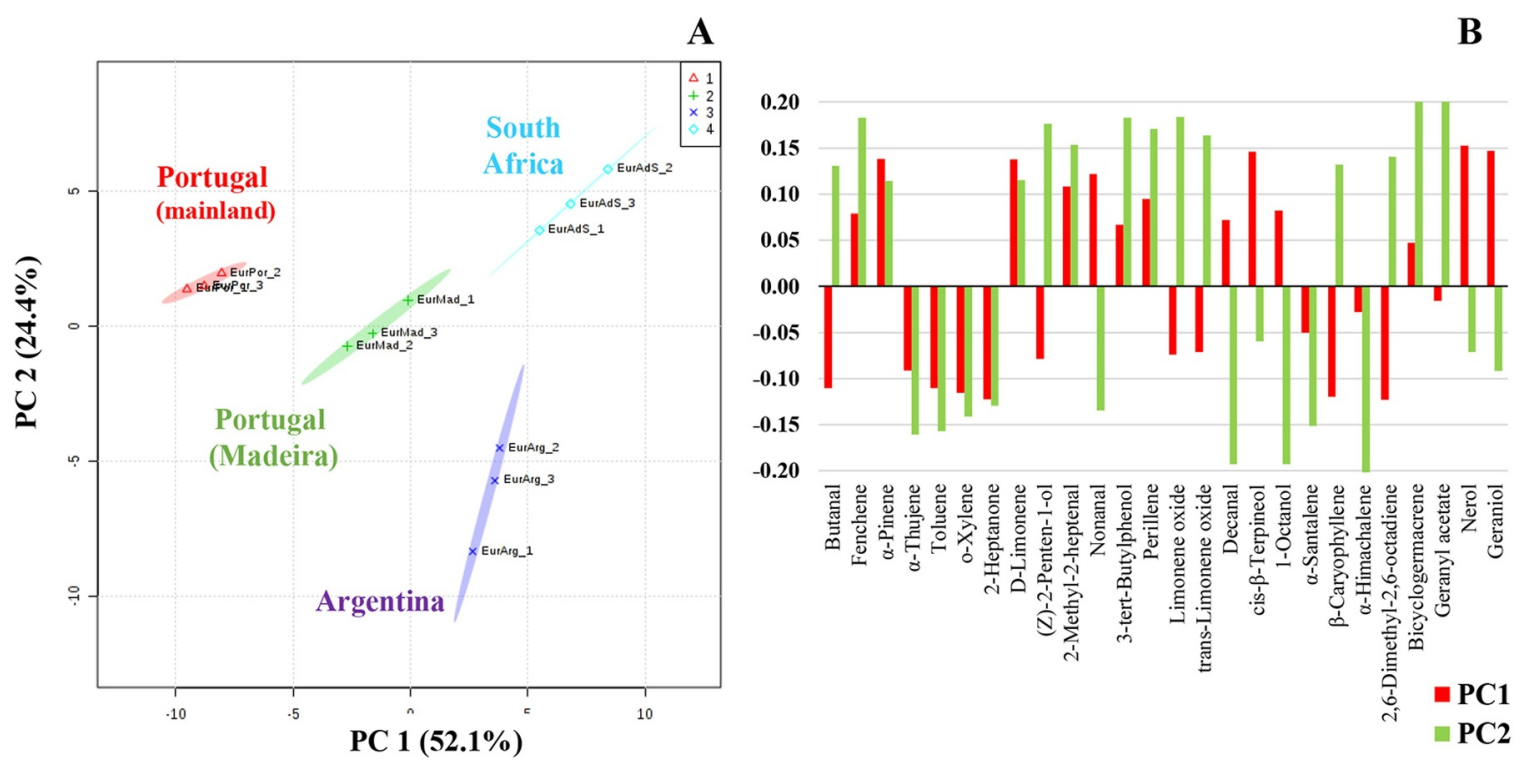

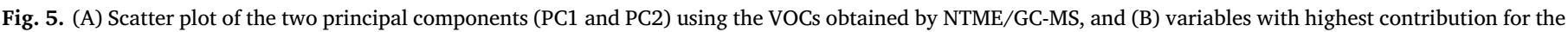
PCA differentiation.

work to discriminate Eureka lemons according to the geographical region, the volatomic data matrix was subjected to a statistical analysis using MetaboAnalyst 4.0 web-based tool [28]. To reduce the data complexity, a normalization method, described in the experimental section, was applied to the raw data previously to the univariate statistical analysis (ANOVA test, $\mathrm{p} \leq 0.05$ ). The ANOVA test was carried out to evaluate the significant statistical differences among the concentrations of VOCs in each sample group. A total of 65 VOCs were found as statistically significant for $(\mathrm{p}<0.05$, Table $2 . \mathrm{SM}$, Supplementary Material). Following this, to assess if there were significant VOCs signatures between each group, multivariate statistical analysis (MVSA) was performed using no supervised (PCA) analysis. The results obtained show four different clusters segregating each of the groups under study (Fig. 5).
The first principal component of PCA (PC1) explains $52.1 \%$ of the variance and separate the lemon varieties produced in Portugal Mainland and Madeira island - from remain varieties, being (ethanol, ethyl octanoate, trans- $\beta$-terpinol, $\alpha$-panansinene, perilla aldehyde and nerol the VOCs responsible for this separation). The second principal component (PC2) contributes for $24.4 \%$ of the total variance of the model and separate the varieties produced in South Africa from those produced in Argentine ( $\alpha$-pinene, $\alpha$-thujene, toluene, 1-butanol, $D$-limonene and 2-methyl-2-heptenal).

Following the PCA analysis, HCA was also performed using the 40 most significant VOCs identified in lemon samples obtained by ANOVA, as described in Section 2.5. This strategy allows a better identification of the inherent clustering patterns between each geographic origin, in complementarity with the statistical analysis carried out previously. 


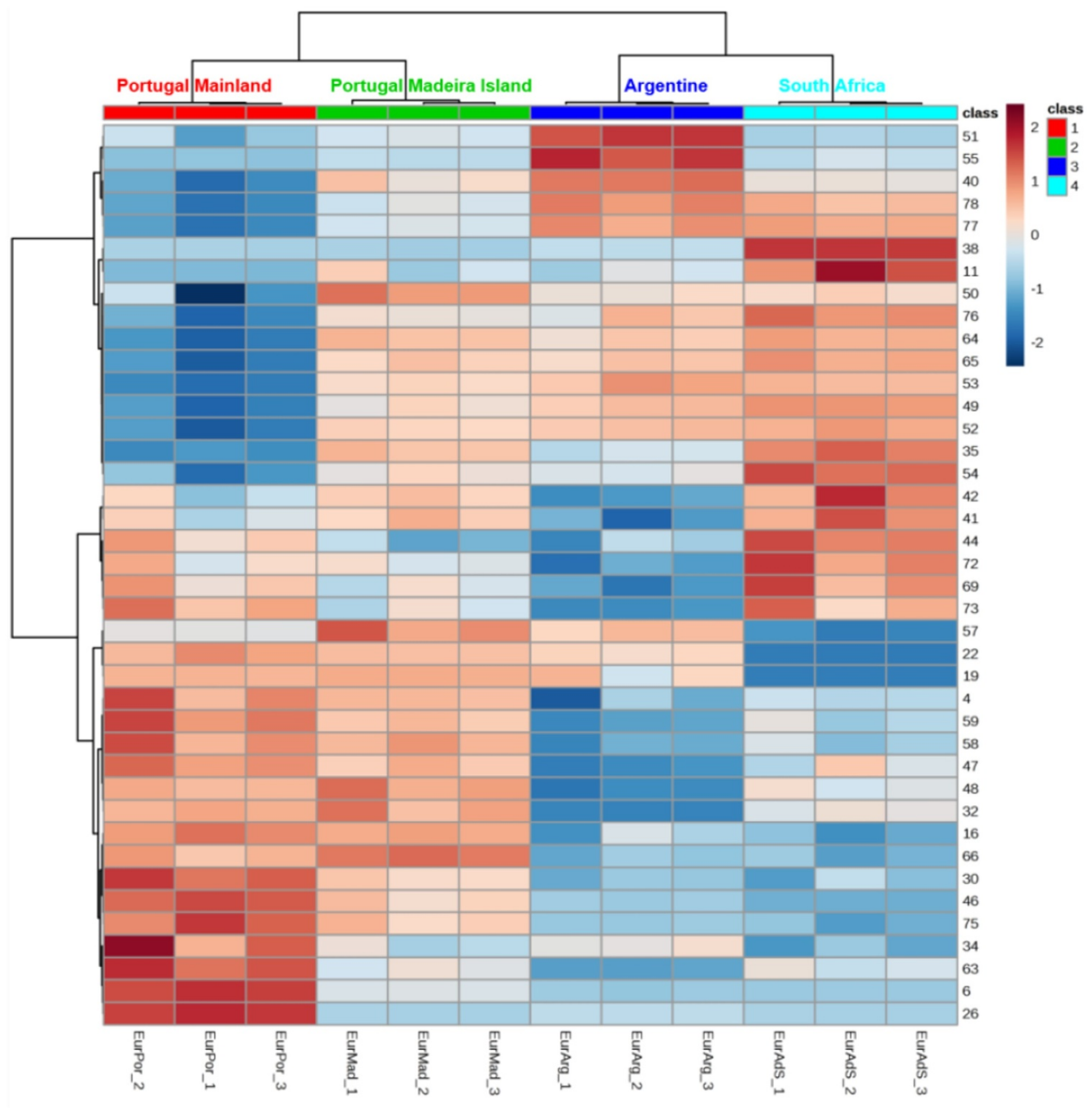

Fig. 6. Hierarchical cluster analysis (HCA). The heat map with the 40 most significant volatiles identified in lemon samples obtained by ANOVA, was generated using Ward algorithm and Pearson distance analysis.

The result of this treatment can be visualized in the heatmap plot (Fig. 6) and in a dendrogram (Fig. 1SM, Supplementary Material).

\subsection{Potential of lemon peels composition}

Among the 75 VOCs identified in this work in lemon peels, most of the main monoterpenes have been previously reported with different bioactivities (Table 3.SM, Supplementary Material). This include sixteen lemon peels VOCs associated to antioxidant [34-38], anti-inflammatory [35,36], antidiabetic [38,39], antileishmanial [40,41], antibacterial [38,40,42-44], antimicrobial [45-47], cytotoxic [41,48], antitumor [49] and antiproliferative activities [50-53], as well as other protective effects against Alzheimer [54] and tuberculosis [55]. Furthermore, many of these VOCs have being also identified in other plants and fruits, as Thymus vulgaris L. [32], Rosmarinus officinalis L. [32], Myrtus communis L. [32], Pistacia lentiscus var. chia [33], Araucaria heterophylla [34], Araucaria bidwillii [34], Citrus hystrix [35], Citrus aurantifolia [36]. Overall, these observations support the strong correlation between the main VOCs identified on the volatile profile of lemon peels and health protective effects, conferring therefore nutraceutical value to lemons and lemon-based foodstuffs. Considering the great diversity of the volatile compounds identified, with differentiated properties, lemon peels can be used to design flavouring agents in food processing, enhancing the quality of the taste and aroma of preservatives, nutrient supplements and other foodstuffs. Moreover, they have the potential to be used in cosmetic formulations for skin, antibacterial and antifungal lotion, toiletries and perfumes [56].

\section{Conclusions}

In this work we reported the identification of lemons according to their geographical origin using a simple analytical layout and a fairly economic experimental set-up. The optimized analytical approach, NTME/GC-MS, allowed a deep and comprehensive insight on the volatile composition of lemon peels (exocarp) from Eureka variety cultivated at different geographical origins - Portugal Madeira Island (Portugal), Argentine and South Africa. A total of 75 VOCs were identified in lemon peels from Eureka variety, a number slightly higher than those reported in previous published works for the same variety. The monoterpenes family are the most dominant VOCs contributing for about $95 \%$ of the volatomic composition of lemon peels from Eureka variety. $\mathrm{D}$-limonene, $\beta$-pinene and $\gamma$-terpinene are the major volatiles identified in lemon peels from the targeted geographical origins.

The VOCs identified in this work were able to differentiate lemons according to their geographic region. Accordingly, butanal, $\alpha$-pinene, $\alpha$-thujene, 2-heptanone, D-limonene, 2-methyl-2-heptenal, nonanal, decanal, 1-octanol, limonene oxide, $\beta$-caryophyllene and 2,6-dimethyl2,6-octadiene, were the VOCs that most contributed for this discrimination. Future work involving more samples and harvesting seasons will certainly improve even further the robustness of the geographical biomarkers here identified. In addition, this analytical approach provides a feasible strategy for authentication of citrus fruits based on volatile fingerprint of its exocarp. NTME/GC-MS reveals a great application potential to other fruits and food matrices, regarding its analytical characterization and authentication based on its 
volatomic composition, enabling effective strategies to support food integrity. The results also suggested a wide range of applications for lemon peels from Eureka variety based on identified VOCs, namely health benefits, potential food additives, as flavour and fragance agents and cosmetic insdustry.

The robustness, high throughput capacity, easy use and sample storage ability for in-field sampling will make NTME very popular extraction approach over a wide range of applications beyond the food analysis here reported. Environmental and clinical analysis will certainly be among those successful applications.

\section{Author statement}

Contribution information of each author:

José Figueira and Priscilla Figueira performed the design of experiments, optimization experimental parameters, method validation, José Figueira, Priscilla Figueira and Jorge Pereira carried out data analysis and manuscript preparation. José S. Câmara performed the conception of study, design of experiments, and manuscript preparation and editing.

\section{Ethical approval}

This article does not contain any studies with human participants or animals performed by any of the authors

\section{Declaration of Competing Interest}

The authors declare that they have no known competing financial interests or personal relationships that could have appeared to influence the work reported in this paper.

\section{Acknowledgements}

This work was supported by FCT-Fundação para a Ciência e a Tecnologia through the CQM Base Fund - UIDB/00674/2020, and Programmatic Fund - UIDP/00674/2020 and the PhD fellowship SFRH/ BD/129630/2017 granted to Priscilla Porto-Figueira) and through Madeira 14-20 Program, project PROEQUIPRAM - Reforço do Investimento em Equipamentos e Infraestruturas Científicas na RAM (M1420-01-0145-FEDER-000008]; and by ARDITI - Agência Regional para o Desenvolvimento da Investigação Tecnologia e Inovação [project M1420-01-0145-FEDER-000005 - Centro de Química da Madeira - CQM + (Madeira 14-20 Program) and Project M1420 - 09-5369-FSE-000001 for the Ph.D. and Post-Doctoral fellowships granted to José A. Figueira and Jorge A. M. Pereira, respectively].

\section{Supplementary materials}

Supplementary material associated with this article can be found, in the online version, at doi:10.1016/j.microc.2020.104933.

\section{References}

[1] A. Geraci, V. Di Stefano, E. Di Martino, D. Schillaci, R. Schicchi, Essential oil components of orange peels and antimicrobial activity, Nat. Prod. Res. 31 (2017) 653-659.

2] G. Kamal, F. Anwar, A. Hussain, N. Sarri, M. Ashraf, Yield and chemical composition of Citrus essential oils as affected by drying pretreatment of peels, Int. Food Res. J. 18 (2011).

[3] J. Kaur, G. Kaur, An insight into the role of citrus bioactives in modulation of colon cancer, J. Funct. Foods 13 (2015) 239-261.

[4] A. Rodríguez, J.E. Peris, A. Redondo, T. Shimada, E. Costell, I. Carbonell, C. Rojas, L. Peña, Impact of D-limonene synthase up-or down-regulation on sweet orange fruit and juice odor perception, Food Chem 217 (2017) 139-150.

[5] A. Gök, Ş.İsmail Kirbaşlar, F. Gülay Kirbaşlar, Comparison of lemon oil composition after using different extraction methods, J. Essent. Oil Res. 27 (2015) 17-22.

[6] S.M. Abd-Elwahab, N.D. El-Tanbouly, M.Y. Moussa, A.R. Abdel-Monem, N.M. Fayek, Antimicrobial and antiradical potential of four agro-waste Citrus peels cultivars, J. Essent. Oil Bear. Plants 19 (2016) 1932-1942.

[7] U.J. Go, I.-Y. Eom, Development of syringe pump assisted headspace sampler, J. Chromatogr. A 1361 (2014) 88-94.

[8] S. Król, B. Zabiegała, J. Namieśnik, Monitoring VOCs in atmospheric air II. Sample collection and preparation, TrAC, Trends Anal. Chem. 29 (2010) 1101-1112.

[9] S. Banihashemi, H. Bagheri, A core-shell titanium dioxide polyaniline nanocomposite for the needle-trap extraction of volatile organic compounds in urine samples, J. Sep. Sci. 40 (2017) 1985-1992.

[10] Y. Li, J. Li, H. Xu, Graphene/polyaniline electrodeposited needle trap device for the determination of volatile organic compounds in human exhaled breath vapor and A549 cell, RSC Adv. 7 (2017) 11959-11968.

[11] K. Kędziora, W. Wasiak, Extraction media used in needle trap devices: Progress in development and application, J. Chromatogr. A 1505 (2017) 1-17.

[12] A. Poormohammadi, A. Bahrami, M. Farhadian, F.G. Shahna, A. Ghiasvand, Development of Carbotrap B-packed needle trap device for determination of volatile organic compounds in air, J. Chromatogr. A 1527 (2017) 33-42.

[13] P. Trefz, S. Kischkel, D. Hein, E.S. James, J.K. Schubert, W. Miekisch, Needle trap micro-extraction for VOC analysis: effects of packing materials and desorption parameters, J. Chromatogr. A 1219 (2012) 29-38.

[14] Z. Ayazi, Application of nanocomposite-based sorbents in microextraction techniques: A review, The Analyst 142 (2017) 721-739.

[15] M.R. Azari, A. Barkhordari, R. Zendehdel, M. Heidari, A novel needle trap device with nanoporous silica aerogel packed for sampling and analysis of volatile aldehyde compounds in air, Microchem. J. 134 (2017) 270-276.

[16] P. Porto-Figueira, J.A.M. Pereira, J.S. Camara, Exploring the potential of needle trap microextraction combined with chromatographic and statistical data to discriminate different types of cancer based on urinary volatomic biosignature, Anal. Chim. Acta 1023 (2018) 53-63.

[17] P. Porto-Figueira, J. Pereira, W. Miekisch, J.S. Camara, Exploring the potential of NTME/GC-MS, in the establishment of urinary volatomic profiles. Lung cancer patients as case study, Sci. Rep. 8 (2018) 13113.

[18] P. Trefz, L. Rosner, D. Hein, J.K. Schubert, W. Miekisch, Evaluation of needle trap micro-extraction and automatic alveolar sampling for point-of-care breath analysis, Anal. Bioanal. Chem. 405 (2013) 3105-3115.

[19] M. Mieth, S. Kischkel, J.K. Schubert, D. Hein, W. Miekisch, Multibed needle trap devices for on site sampling and preconcentration of volatile breath biomarkers, Anal. Chem. 81 (2009) 5851-5857.

[20] L.M. Feijó Barreira, Y. Xue, G. Duporté, J. Parshintsev, K. Hartonen, M. Jussila, M. Kulmala, M.-L. Riekkola, Potential of needle trap microextraction-portable gas chromatography-mass spectrometry for measurement of atmospheric volatile compounds, Atmos. Meas. Tech. (2016) 3661-3671.

[21] M. Heidari, A. Bahrami, A.R. Ghiasvand, F.G. Shahna, A.R. Soltanian, A needle trap device packed with a sol-gel derived, multi-walled carbon nanotubes/silica composite for sampling and analysis of volatile organohalogen compounds in air, Anal. Chim. Acta 785 (2013) 67-74.

[22] I.-Y. Eom, A.-M. Tugulea, J. Pawliszyn, Development and application of needle trap devices, J. Chromatogr. A 1196 (2008) 3-9.

[23] H. Bagheri, Z. Ayazi, A. Aghakhani, A novel needle trap sorbent based on carbon nanotube-sol-gel for microextraction of polycyclic aromatic hydrocarbons from aquatic media, Anal. Chim. Acta 683 (2011) 212-220.

[24] A. Barkhordari, M.R. Azari, R. Zendehdel, M. Heidari, Analysis of formaldehyde and acrolein in the aqueous samples using a novel needle trap device containing nanoporous silica aerogel sorbent, Environ. Monit. Assess. 189 (2017) 171.

[25] N. Heidari, A. Ghiasvand, S. Abdolhosseini, Amino-silica/graphene oxide nanocomposite coated cotton as an efficient sorbent for needle trap device, Anal. Chim. Acta 975 (2017) 11-19.

[26] I.Y. Eom, J. Pawliszyn, Simple sample transfer technique by internally expanded desorptive flow for needle trap devices, J. Sep. Sci. 31 (2008) 2283-2287.

[27] J. Gonçalves, J. Figueira, F. Rodrigues, J.S. Câmara, Headspace solid-phase microextraction combined with mass spectrometry as a powerful analytical tool for profiling the terpenoid metabolomic pattern of hop-essential oil derived from Saa variety, J. Sep. Sci. (2012) 2282-2296.

[28] J. Chong, O. Soufan, C. Li, I. Caraus, S. Li, G. Bourque, D.S. Wishart, J. Xia, MetaboAnalyst 4.0: Towards more transparent and integrative metabolomics analysis, Nucleic Acids Res 46 (2018) W486-W494.

[29] X. Zang, W. Liang, Q. Chang, T. Wu, C. Wang, Z. Wang, Determination of volatile organic compounds in pen inks by a dynamic headspace needle trap device combined with gas chromatography-mass spectrometry, J. Chromatogr. A 1513 (2017) 27-34.

[30] J.M. Sanchez, Effects of packing density, flow and humidity on the performance of needle trap devices, J. Chromatogr. A 1369 (2014) 18-25.

[31] M.-L. Lota, D. de Rocca Serra, F. Tomi, C. Jacquemond, J. Casanova, Volatile components of peel and leaf oils of lemon and lime species, J. Agric. Food Chem. 50 (2002) 796-805.

[32] S. Zhong, J. Ren, D. Chen, S. Pan, K. Wang, S. Yang, G. Fan, Free and bound volatile compounds in juice and peel of Eureka lemon, Food Sci. Technol. Res. 20 (2014) $167-174$

[33] H. Zhang, Y. Xie, C. Liu, S. Chen, S. Hu, Z. Xie, X. Deng, J. Xu, Comprehensive comparative analysis of volatile compounds in citrus fruits of different species, Food Chem 230 (2017) 316-326.

[34] H.M. Ahmed, S. Tavaszi-Sarosi, Identification and quantification of essential oil content and composition, total polyphenols and antioxidant capacity of Perilla frutescens (L.) Britt, Food Chem 275 (2019) 730-738.

[35] N. Halla, S.A. Heleno, P. Costa, I.P. Fernandes, R.C. Calhelha, K. Boucherit, A.E. Rodrigues, I.C.F.R. Ferreira, M.F. Barreiro, Chemical profile and bioactive properties of the essential oil isolated from Ammodaucus leucotrichus fruits 
growing in Sahara and its evaluation as a cosmeceutical ingredient, Ind. Crops Prod. 119 (2018) 249-254.

[36] H. Li, Y. Ge, Z. Luo, Y. Zhou, X. Zhang, J. Zhang, Q. Fu, Evaluation of the chemical composition, antioxidant and anti-inflammatory activities of distillate and residue fractions of sweet basil essential oil, J. Food Sci. Techno. 54 (2017) 1882-1890.

[37] M. Lubinska-Szczygieł, A. Różańska, J. Namieśnik, T. Dymerski, R.B. Shafreen, M. Weisz, A. Ezra, S. Gorinstein, Quality of limes juices based on the aroma and antioxidant properties, Food Control 89 (2018) 270-279.

[38] M.F. Mahomoodally, A. Mollica, A. Stefanucci, M. Zakariyyah Aumeeruddy, R. Poorneeka, G. Zengin, Volatile components, pharmacological profile, and computational studies of essential oil from Aegle marmelos (Bael) leaves: A functional approach, Ind. Crops Prod. 126 (2018) 13-21.

[39] F. Alam, Z. Shafique, S.T. Amjad, M.H.H. Bin Asad, Enzymes inhibitors from natural sources with antidiabetic activity: a review, Phytother. Res. 33 (2019) 41-54.

[40] V.D. da Silva, F. Almeida-Souza, A.M. Teles, P.A. Neto, R. Mondego-Oliveira, N.E. Mendes Filho, N.N. Taniwaki, A.L. Abreu-Silva, K.d.S. Calabrese,

V.E. Mouchrek Filho, Chemical composition of Ocimum canum Sims. essential oi and the antimicrobial, antiprotozoal and ultrastructural alterations it induces in Leishmania amazonensis promastigotes, Ind. Crops Prod. 119 (2018) 201-208.

[41] V.P. da Silva, C.C.F. Alves, M.L.D. Miranda, L.C. Bretanha, M.P. Balleste, G.A. Micke, E.V. Silveira, C.H.G. Martins, M.A.L.V. Ambrosio, T. de Souza Silva, D.C. Tavares, L.G. Magalhães, F.G. Silva, M.B. Egea, Chemical composition and in vitro leishmanicidal, antibacterial and cytotoxic activities of essential oils of the Myrtaceae family occurring in the Cerrado biome, Ind. Crops Prod. 123 (2018) 638-645.

[42] M.D.S. Costa, J.E. Rocha, F.F. Campina, A.R.P. Silva, R.P. Da Cruz, R.L.S. Pereira, L.J. Quintans-Júnior, I.R.A. De Menezes, A.A. De S. Araújo, T.S. De Freitas, A.M.R. Teixeira, H.D.M. Coutinho, Comparative analysis of the antibacterial and drug-modulatory effect of d-limonene alone and complexed with $\beta$-cyclodextrin, Eur. J. Pharm. Sci. 128 (2019) 158-161.

[43] M. Fadil, K. Fikri-Benbrahim, S. Rachiq, B. Ihssane, S. Lebrazi, M. Chraibi, T. Haloui, A. Farah, Combined treatment of Thymus vulgaris L., Rosmarinus officinalis L. and Myrtus communis L. essential oils against Salmonella typhimurium: optimization of antibacterial activity by mixture design methodology, Eur. J. Pharm. Biopharm. 126 (2018) 211-220.

[44] S. Nardoni, V.V. Ebani, C. D'Ascenzi, L. Pistelli, F. Mancianti, Sensitivity of Entomopathogenic fungi and bacteria to plants secondary metabolites, for an alternative control of rhipicephalus (boophilus) microplus in cattle, Front. Pharmacol. 9 (2018).

[45] E. Dănilă, Z. Moldovan, M. Popa, M.C. Chifiriuc, A.D. Kaya, M.A. Kaya, Chemical composition, antimicrobial and antibiofilm efficacy of C. limon and L. angustifolia EOs and of their mixtures against Staphylococcus epidermidis clinical strains, Ind.
Crops Prod. 122 (2018) 483-492.

[46] G.d.S. Dannenberg, G.D. Funck, W.P.d. Silva, Â.M. Fiorentini, Essential oil from pink pepper (Schinus terebinthifolius Raddi): chemical composition, antibacterial activity and mechanism of action, Food Control 95 (2019) 115-120.

[47] H. Zhang, Z. Lou, X. Chen, Y. Cui, H. Wang, X. Kou, C. Ma, Effect of simultaneous ultrasonic and microwave assisted hydrodistillation on the yield, composition, antibacterial and antibiofilm activity of essential oils from Citrus medica L. var. sarcodactylis, J. Food Eng. 244 (2019) 126-135.

[48] V.D. da Silva, F. Almeida-Souza, A.M. Teles, P.A. Neto, R. Mondego-Oliveira, N.E. Mendes Filho, N.N. Taniwaki, A.L. Abreu-Silva, K. da Silva Calabrese, V.E. Mouchrek Filho, Chemical composition of Ocimum canum Sims. essential oil and the antimicrobial, antiprotozoal and ultrastructural alterations it induces in Leishmania amazonensis promastigotes, Ind. Crops Prod. 119 (2018) 201-208.

[49] C.E. Assmann, F.C. Cadoná, B.d.S.R. Bonadiman, E.B. Dornelles, G. Trevisan, I.B.M. da Cruz, Tea tree oil presents in vitro antitumor activity on breast cancer cells without cytotoxic effects on fibroblasts and on peripheral blood mononuclear cells, Biomed. Pharmacother. 103 (2018) 1253-1261.

[50] W.M. Elkady, I.M. Ayoub, Chemical profiling and antiproliferative effect of essential oils of two Araucaria species cultivated in Egypt, Ind. Crops Prod 118 (2018) 188-195.

[51] L.T. García, A.F. Leal, É.M. Moreno, E.E. Stashenko, H.J. Arteaga, Differential antiproliferative effect on K562 leukemia cells of Lippia alba (Verbenaceae) essential oils produced under diverse growing, collection and extraction conditions, Ind. Crops Prod. 96 (2017) 140-148.

[52] H. Mo, R. Jeter, A. Bachmann, S.T. Yount, C.-L. Shen, H. Yeganehjoo, The potential of isoprenoids in adjuvant cancer therapy to reduce adverse effects of statins, Front. Pharmacol. 9 (2019).

[53] K. Spyridopoulou, A. Tiptiri-Kourpeti, E. Lampri, E. Fitsiou, S. Vasileiadis, M. Vamvakias, H. Bardouki, A. Goussia, V. Malamou-Mitsi, M.I. Panayiotidis, A. Galanis, A. Pappa, K. Chlichlia, Dietary mastic oil extracted from Pistacia lentiscus var. chia suppresses tumor growth in experimental colon cancer models, Scient. Rep. 7 (2017) 3782 -3782.

[54] T. Satou, Y. Hanashima, I. Mizutani, K. Koike, The effect of inhalation of essential oil from Rosmarinus officinalis on scopolamine-induced Alzheimer's type dementia model mice, Flavour Fragrance J. 33 (2018) 230-234.

[55] E. Sieniawska, R. Sawicki, M. Swatko-Ossor, A. Napiorkowska, A. Przekora, G. Ginalska, M. Swatko-Ossor, E. Augustynowicz-Kopec, The effect of combining natural terpenes and antituberculous agents against reference and clinical Mycobacterium tuberculosis strains, Molecules 23 (2018) 176.

[56] N.S. Dosoky, W.N. Setzer, Biological activities and safety of citrus spp. essential oils, Int. J. Mol. Sci. 19 (2018). 